\title{
Raised concentrations of platelet activating factor in colonic mucosa of Crohn's disease patients
}

I Sobhani, S Hochlaf, Y Denizot, C Vissuzaine, Emmanuel Rene, J Benveniste, Migwel M J Lewin, Michel Mignon

\begin{abstract}
Platelet activating factor (PAF-ACETHER or PAF) and precursors of platelet activating factor were investigated in 26 patients with acute Crohn's disease and in 10 healthy controls. Platelet activating factor, lyso platelet activating factor, and alkyl acyl glycerophosphocholine, were determined in colonic mucosal biopsies in patients with acute Crohn's disease, during prednisolone therapy, and in remission. Biopsy specimens were submitted to histopathology examination and to phospholipid extraction. Platelet activating factor, lyso platelet activating factor, and alkyl acyl glycerophosphocholine were found in patients with acute Crohn's disease and in remission as well as in controls. Whatever the site of the biopsy, the level of platelet activating factor in colonic mucosa was higher $(\mathbf{p}<\mathbf{0 . 0 1})$ in Crohn's disease than in controls. There was no correlation between the level of colonic PAF-ACETHER and age, sex, Crohn's disease activity index, and biological parameters in sera. Although concentrations of colonic platelet activating factor content were higher $(\mathbf{p}<\mathbf{0 . 0 1})$ when colonic mucosa displayed cell infiltration, they were neither related to the severity nor the type of inflammatory cells. Platelet activating factor decreases with prednisolone therapy and might return to normal concentrations in quiescent patients. Lyso platelet activating factor and alkyl acyl glycerophosphocholine were not significantly higher in Crohn's disease than in controls. These data suggest that platelet activating factor may be involved in the pathogenesis of Crohn's disease and that it could be used as a marker of the mucosal activity of the disease.

(Gut 1992; 33: 1220-1225)
\end{abstract}

Crohn's disease is a recurrent inflammatory disorder of unknown aetiology and pathogenesis. Histologically, Crohn's disease is characterised by an important infiltration of proinflammatory cells involving the entire gastrointestinal tract from the mouth to the anus. The mechanisms underlying the inflammatory process are poorly understood. When infiltrated by inflammatory cells, the mucosa is known to generate a variety of inflammatory lipidic mediators ${ }^{1-3}$ such as arachidonic acid metabolites - for example, prostaglandins, thromboxane, and leukotrienes - and platelet activating factor (also called platelet activating factor acether).

Platelet activating factor, first described in 1972 as platelet activating factor ${ }^{+}$has been identified as 1-0-alkyl-2-0-acetyl-sn-glycero-3phosphocholine. Platelet activating factor is a lipid mediator derived from membrane phospholipids and involving in hypersensitivity and inflammatory reactions. ${ }^{5}$ It is synthetised by numerous human cell types, including neutrophils, monocytes, macrophages, platelets, eosinophils, vascular endothelial cells, and several cancer cell lines including gastric epithelial (HGT1) cells. ${ }^{6}{ }^{12}$ It is capable of inducing inflammatory reactions such as increased vascular permeability, leucocyte adhesion and chemotaxis. Some of the manifestations of septic shock, such as hypotension, haemoconcentration, and gastrointestinal ulceration were reported to be mimicked after intravenous administration of platelet activating factor in rats suggesting that it plays a role in this syndrome. ${ }^{13-18}$ At present, little is known about the role of platelet activating factor in ulcerative diseases of the gastrointestinal tract in man, although it has been reported in mucosal biopsy specimens from patients with ulcerative colitis and Crohn's disease. ${ }^{19-21}$

The aim of this study was to determine amounts of platelet activating factor and metabolites (lyso platelet activating factor and alkylacyl-glycerophosphocholine). In the intestinal mucosa of patients with Crohn's disease related to disease activity in order to assess the possible role of platelet activating factor in the pathogenesis of Crohn's disease.

\section{Methods}

\section{SUBJECTS}

Twenty six patients ( 12 men, 14 women; mean age 28 yr, ranging 30-80) with active Crohn's disease (duration of the disease one to 11 years) located to the colon (15), the ileum (three) or both (eight), were investigated. Their diagnoses were based on Morson's morphologic criteria and the activity of the disease was assessed on the Best index (CDAI) and biological parameters (erythrocyte sedimentation rate (ESR), white blood cell count (WBC), platelets, $\alpha^{2}$ globulin).

Ten healthy volunteers (five men, five women; mean age $31 \mathrm{yr}$, ranging $30-80$ ) were investigated as controls.

\section{COLONOSCOPY}

All individuals underwent endoscopy examination of the colon (Olympus $\mathrm{CF}_{20} \mathrm{HL}$ ) under sedation (midazolam, noramidopyrin, trimebutin), after colonic preparation with PEG 4000 (4 1) and before anti-inflammatory or immunosuppressive therapy.

Five of the 26 Crohn's disease patients underwent a flexible sigmoidoscopy after four weeks of 
$1 \mathrm{mg} / \mathrm{kg} /$ day prednisolone therapy. A third flexible sigmoidoscopy was performed one month after cessation of all therapy when the disease had been considered in stable remission with no symptoms of recurrence.

Biopsy specimens were taken from nonulcerated areas in right and left sides of the colon when Crohn's lesions were present and from macroscopically normal mucosa in control subjects and in the five Crohn's disease patients after healing.

\section{HISTOPATHOLOGY}

Biopsy specimens were fixed in Bouin's aqueous solution. Sections were stained with haematoxylin and eosin. Mucosal infiltration by inflammatory cells was evaluated as: absent $(0)$, moderate $(+)$, mild $(++)$, intense $(+++)$ by an experienced pathologist who was blinded to the results of platelet activating factor.

\section{PLATELET ACTIVATING FACTOR ASSAY}

Biopsy specimens were transferred into tubes with $80 \%$ ethanol as previously described for ethanolic platelet activating factor extraction from cells $s^{23}$ as well as from biopsies ${ }^{19-2124}$ and frozen at $-20^{\circ} \mathrm{C}$ until assayed for platelet activating factor activity. Twenty four hours before platelet activating factor assay, biopsy specimens in $80 \%$ ethanol were cut into small pieces (less than $1 \mathrm{mg}$ ). Extraction of platelet activating factor was performed during 10 hours at $-4^{\circ} \mathrm{C}$ using a 'roller'. All samples were directly measured using the aggregation of washed rabbit platelets. Rabbit platelets were washed as described previously ${ }^{25}$ : aspirinated platelets $\left(1.6 \times 10^{8}\right)$ in $300 \mu l$ Tyrode's solution, containing $2.5 \%$ gelatin and the ADP scavenger mixture creatine phosphate (1 $\mathrm{mM})$ and creatine phosphokinase $(10 \mathrm{IU} / \mathrm{ml})$ were stirred in an aggregometer (Icare, Marseille, France). The aggregating activity of the samples was measured over the linear portion of the calibration curve obtained with 5-50 pg of synthetic platelet activating factor.

\section{ASSAY FOR LYSO PLATELET ACTIVATING FACTOR} Lyso platelet activating factor was chemically acetylated into platelet activating factor, extracted in ethanol and measured as previously described. ${ }^{23}$ Briefly, the ethanolic extracts were dried under an air stream, mixed with $200 \mu \mathrm{l}$ pyridine and acetic anhydride and kept for 18 hours in the dark, at room temperature. The extracts were evaporated and traces of pyridine removed with dichloromethane. Samples recovered with $100 \mu \mathrm{l}$ of $60 \%$ ethanol and then assayed as described above. The amount of lyso platelet activating factor was calculated as the difference between the quantity of platelet activating factor measured after and before acetylation of the samples.

ASSAY FOR ALKYL-ACYL-

GLYCEROPHOSPHOCHOLINE (AAGPC)

Alkyl acyl glycerophosphocholine were measured after alkaline hydrolysis and subsequent acetylation. ${ }^{23}$ Briefly, aliquots of the dried extracts were treated with $0.03 \mathrm{~N} \mathrm{NaOH}$ in methanol for two hours at room temperature. The $\mathrm{pH}$ was adjusted to $7 \cdot 0$ with $1 \mathrm{~N} \mathrm{HCl}$ and the mixture was evaporated to dryness. The dried residues were then acetylated as described above and platelet activating factor was assayed. The amount of alkyl acyl glycerophosphocholine was calculated as the difference between the levels of platelet activating factor measured before and after alkaline hydrolysis and acetylation.

\section{CHARACTERISATION OF PLATELET ACTIVATING} FACTOR

For further characterisation of the platelet aggregation molecule, platelet activating factor extracted from biopsy specimens from patients with Crohn's disease was pooled, dried and eluted on high performance liquid chromatography. ${ }^{2124-28}$ The platelet aggregating activity was eluted from 18 to 21 minutes - that is, with a retention time similar to that of synthetic platelet activating factor. The efficiency of this procedure averaged $80 \%$ using $\left[{ }^{3} \mathrm{H}\right]$ platelet activating factor as internal standard. In addition to its ADP and aracachidonic acid independent aggregating activity on rabbit platelets, the lipidic material was further characterised as platelet activating factor on the basis of the following criteria: (a) its aggregating activity in the presence of $0.1 \mathrm{mM}$ BN 52021 , a specific platelet activating factor receptor antagonist ${ }^{26}$; (b) its aggregating activity after incubation of the samples with $10 \mu \mathrm{g} / \mathrm{ml}$ phospholipase $A_{2}$ from hog pancreas and with $100 \mu \mathrm{g} / \mathrm{ml}$ lipase $A_{1}$ from $R$ arrhizus $^{27}$; (c) its retention time during high performance liquid chromatography analysis using phosphatidylcholine, lysophosphatidylcholine, and synthetic C-18 platelet activating factor as standards. ${ }^{28}$

\section{STATISTICAL ANALYSIS}

All values are expressed as mean (standard error of the mean (SEM)). The Mann-Whitney U rank sum test and Spearman rank correlation test were used for statistical evaluation.

The study was approved by the Ethical Committee of the Bichat Hospital.

\section{Results}

CLINICAL AND BIOLOGICAL PARAMETERS

In acute Crohn's disease, the Best index (CDAI) was more than 150 in all patients with mean (SEM) 203 (23). Biological parameters were consistent with systemic inflammation (m $(\mathrm{SEM})): \quad \mathrm{ESR}=51 \quad(5) \mathrm{mm} / \mathrm{h}, \quad \mathrm{WBC}=10322$ (632)/dl, platelets $=439(31) 10^{3} / \mathrm{del}$ and $\alpha_{2}$ globulin $=8 \cdot 4(0 \cdot 4) \mathrm{g} / \mathrm{l}$. All these parameters were normal in patients with Crohn's disease in remission and in controls. controls whereas ileal and/or colonic ulcerations 


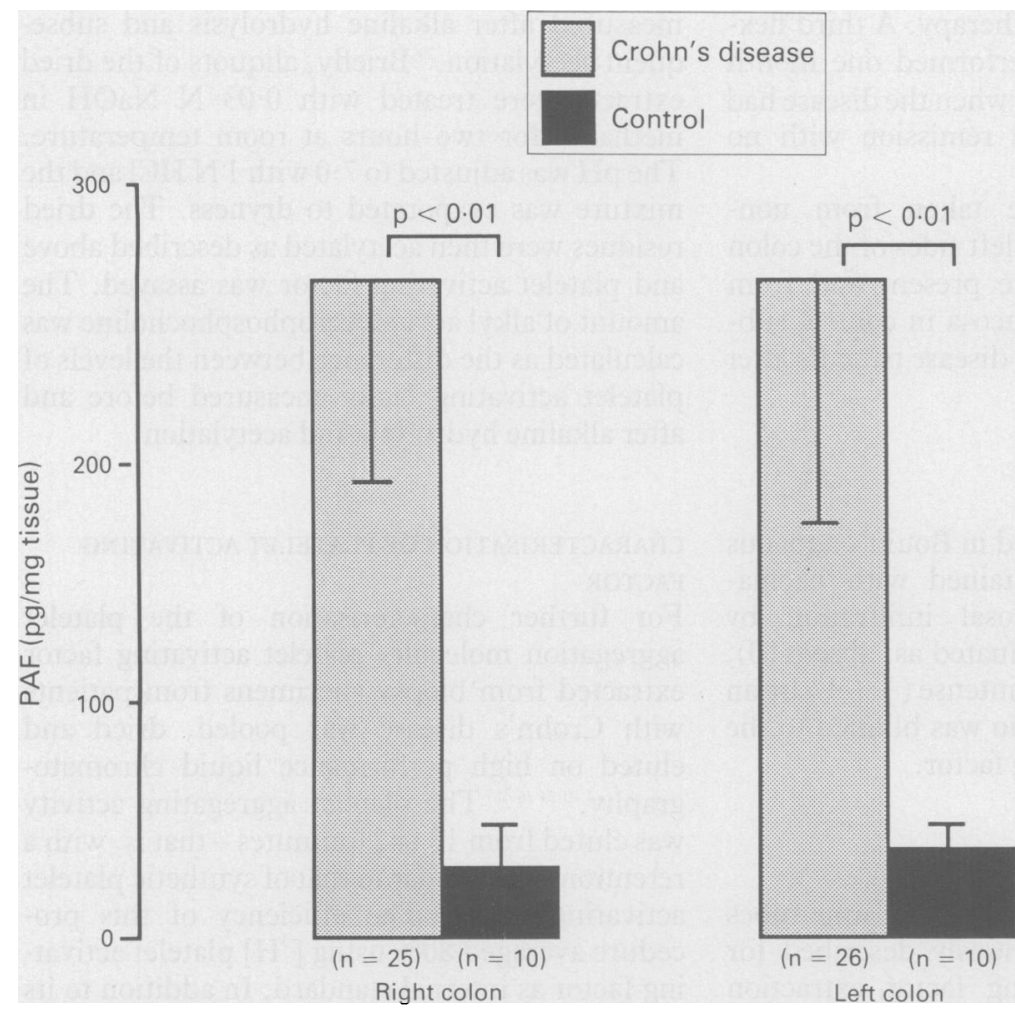

Figure 1: Values are expressed as means (SEM). ( $n$ ) denotes the number of individuals investigated. $P A F=$ platelet activating factor.

and inflamed mucosa were noted in all Crohn's disease patients before prednisolone therapy. Flexible sigmoidoscopy showed occasional ulceration in the left colon in four of five patients examined during prednisolone therapy and normal mucosa in all patients with Crohn's disease examined in remission.

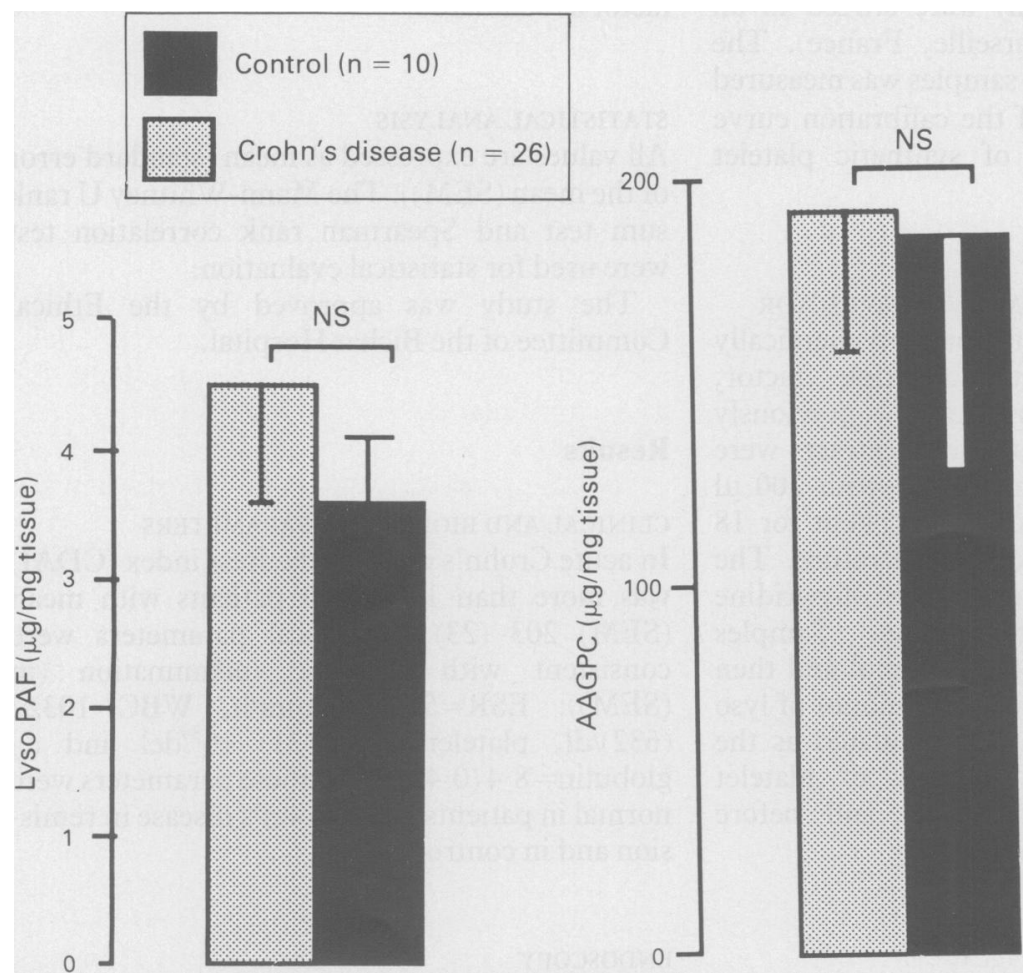

Figure 2: Values are expressed as mean $(S E M) .(n)$ denotes the number of individuals investigated; NS: not significant.

\section{HISTOPATHOLOGY}

None of the 10 controls had mucosal infiltration by inflammatory cells whereas in patients with active Crohn's disease, inflammatory cells were present in at least one site (left or right) of the colon (26) or in both (23). Mucosal infiltration by inflammatory cells was ranged as absent, moderate, mild, intense in 3, 8, 9, 6 patients respectively in the right site of the colon and in $4,6,7,8$ patients respectively in the left site of the colon. After four weeks after prednisolone therapy (five) the inflammation decreased to a lesser extent: two with moderate mucosal inflammatory cell infiltration remained at moderate, two with mild musocal inflammatory cell infiltration returned to normal (absent) and one with intense mucosal inflammatory cell infiltration decreased to mild. The inflammatory cells were absent in the colonic mucosa of Crohn's disease patients examined in remission.

\section{PLATELET ACTIVATING FACTOR IN COLONIC}

BIOPSIES

The platelet activating factor content of mucosal samples was significantly $(p<0.01)$ higher in patients with Crohn's disease than in controls, both in the right $(270(100) v 25(11) \mathrm{pg} / \mathrm{mg}$ net weight) and left colon (280 (110) v $30(8) \mathrm{pg} /$ mgW) (Fig 1).

Whatever the site of the biopsies, lyso platelet activating factor and alkyl acyl glycerophosphocholine concentrations were not significantly higher in Crohn's disease than in controls $(4.5$ $(1 \cdot 2) v 3.4(0 \cdot 8) \mu \mathrm{g} / \mathrm{mgW}$ and $190(30) v 180(60)$ $\mu \mathrm{g} / \mathrm{mgW}$ respectively (Fig 2 ).

COMPARISON OF PLATELET ACTIVATING FACTOR CONCENTRATIONS WITH CLINICAL, BIOCHEMICAL, AND HISTOLOGICAL PARAMETERS

The mucosal content of platelet activating factor was higher $(\mathrm{p}<0.01)$ in inflamed than in noninflamed mucosa, but no significant correlation was observed with the severity of mucosal inflammation (Fig 3). Even the platelet activating factor levels were higher when mucosal histology examination showed granuloma (310 (70) $\mathrm{pg} / \mathrm{mgW}$ ) or mononuclear cells (300 (110) $\mathrm{pg} / \mathrm{mgW})$ than polymorphonuclear cells $(170(80)$ $\mathrm{pg} / \mathrm{mgW}$ ), there was no significant correlation between colonic platelet activating factor content and mucosal infiltration of different type of inflammatory cells (Fig 4).

There was no correlation between the mucosal content of platelet activating factor and the level of age $\left(r^{\prime}: 0 \cdot 24 ; p=0 \cdot 16\right)$, sex $\left(r^{\prime}: 0 \cdot 10 ; p=0 \cdot 57\right)$, CDAI $\left(r^{\prime}: 0 \cdot 16 ; p=0 \cdot 44\right), \operatorname{ESR}\left(r^{\prime}: 0 \cdot 1 ; p=0 \cdot 6\right)$, platelets $\left(\mathrm{r}^{\prime}: 0 \cdot 14 ; \mathrm{p}=0 \cdot 48\right)$, WBC $\left(\mathrm{r}^{\prime}: 0 \cdot 3 ; \mathrm{p}=\right.$ $0 \cdot 1)$, and $\alpha_{2}$ globulin $\left(r^{\prime}: 0.3 ; p=0.09\right)$.

\section{PLATELET ACTIVATING FACTOR LEVELS AFTER} PREDNISOLONE THERAPY

Five patients with Crohn's disease after treatment with prednisolone underwent flexible sigmoidoscopy. The amount of colonic platelet activating factor content decreased significantly $(p<0.05)$ in four and returned to normal values in three patients (Fig 5). There was no significant 


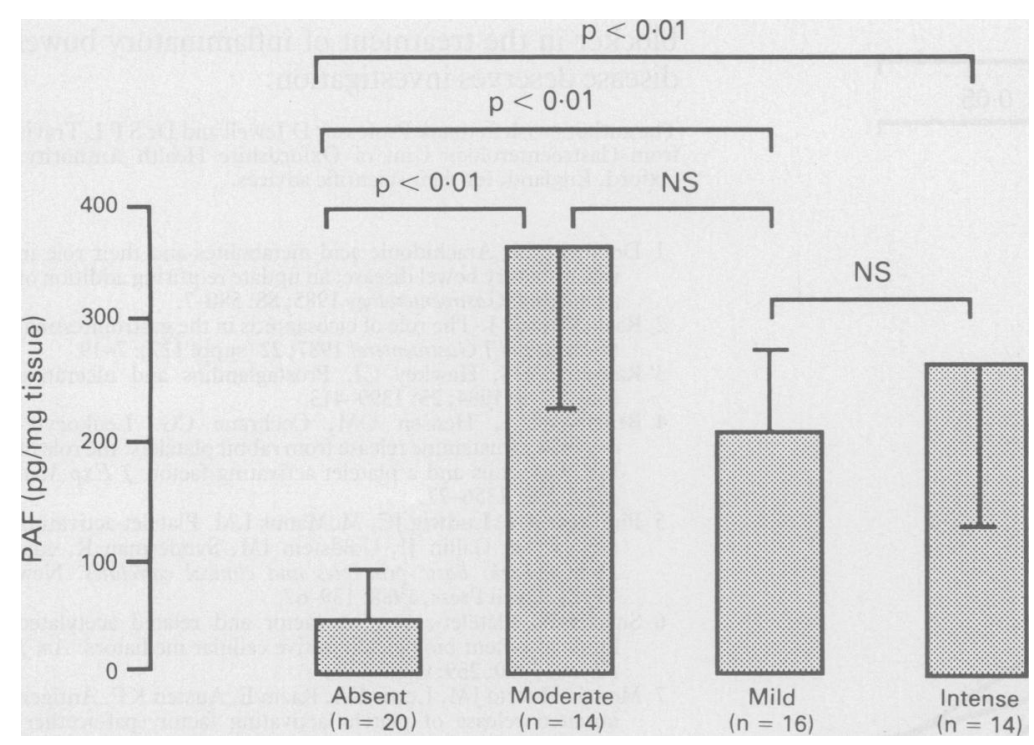

Figure 3: Values are expressed as mean $(S E M)$. (n) denotes the number of individuals investigated; NS: not significant.

difference on mucosal content of platelet activating factor in patients with Crohn's disease in remission than in controls $(\mathrm{p}=0 \cdot 07)$.

\begin{abstract}
Discussion
The results obtained in this study indicate that the mucosal platelet activating factor content is considerably increased in patients with acute Crohn's disease, decreased by glucocorticoid therapy and may return to normal concentrations in quiescent Crohn's disease. Platelet activating factor was extracted from biopsy specimens using ethanolic extraction as previously reported by us $^{24}$ and others. ${ }^{19-20}$ Biopsy specimens should be conserved in $80 \%$ ethanol and frozen at $-20^{\circ} \mathrm{C}$ until assayed for platelet activating factor activity. In these conditions, the platelet activating factor acetylhydrolase activity (the enzyme which cleaves platelet activating factor into the inactive lyso platelet activating factor) which is naturally present in biopsy specimens is inactivated. One freeze treatment did not affect the acetylhydrolase activity. Ethanolic extraction is now a common method of extracting platelet activating factor from various organs including biopsy specimens. ${ }^{19-21} 2324$ In the present study the aggregating activity of materials obtained from patients with Crohn's disease was characterised as
\end{abstract}

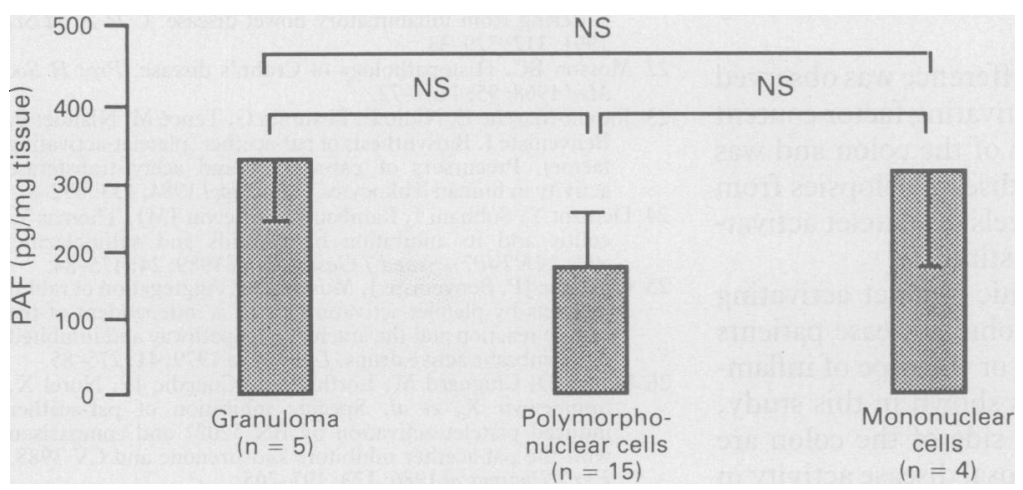

Figure 4: Values are expressed as mean (SEM). ( $n$ ) denotes the number of individuals investigated; NS: not significant. platelet activating factor according to: (i) its retention time from high performance liquid chromatography which was similar to that of synthetic platelet activating factor; (ii) its inhibition by specific platelet activating factor antagonist and phospholipase A2 (PLA2) and no by PLA1. ${ }^{25-28}$

The possibility that platelet activating factor may be involved in Crohn's disease has been suggested by Kald et al. ${ }^{20}$ These authors have shown that colonic platelet activating factor content was significantly .increased irrespective of colonic inflammation. Our data supported by quantification of mucosal inflammatory cell infiltration, suggest that the increase of platelet activating factor levels in colonic mucosa of Crohn's disease patients are neither related to the severity nor the type of inflammatory cell infiltration. So far, the cellular origin of platelet activating factor from colonic mucosa remains unclear. The lack of correlation between platelet activating factor content and the severity of inflammation in colonic mucosa shown by our present findings, speaks against inflammatory cells as the sole source of platelet activating factor synthesis. In addition platelet activating factor was also found, although to a lesser extent in normal, uninflamed mucosa. The possibility that intestinal epithelial cells may produce platelet activating factor has been suggested by Kald et al. ${ }^{20}$ Although the present investigation did not reveal more platelet activating factor in colonic mucosa in patients with Crohn's disease in remission than in controls, this hypothesis could be possible but needs further investigations. Alternatively, the presence of platelet activating factor reflects not only inflammatory cell infiltration, but may also represent a stage of inflammatory amplification in which inflammatory cells are about to be recruited. This hypothesis seems likely, because Crohn's disease patients with inflamed mucosa had a very high mucosal platelet activating factor content that decreased during prednisolone therapy, and sometimes returned to normal levels in remission. It is well known the Crohn's disease is a diffuse lesion of the entire gastrointestinal tract. We have not investigated platelet activating factor content, however, in duodenal or jejunal mucosa of Crohn's disease patients, therefore we have no information as to whether the increase of platelet activating factor levels occurs all along the gastrointestinal tract.

Numerous data have suggested a role of arachidonic acid metabolites in the pathophysiology of various gastrointestinal disorders. For example, enhanced synthesis of protaglandins, thromboxane $\mathrm{A}_{2}$ and prostacyclin and leukotriene $\mathrm{B} 4$ have all been shown in chronic inflammatory bowel diseases. ${ }^{2329-32}$ It has been reported that PLA2 activity contributes to the inflammatory process and promotes the formation of arachidonic acid metabolites. ${ }^{133}$ Of interest, two metabolic steps are involved in platelet activating factor biosynthesis: first, $\mathrm{PLA}_{2}$ acts on cholinecontaining membrane alkyl-phospholipids resulting in the production of lyso platelet activating factor - that is, 1-0-alkyl-sn-glycero-3phosphocholine" ; and, second, this lyso platelet activating factor compound is acetylated by an 


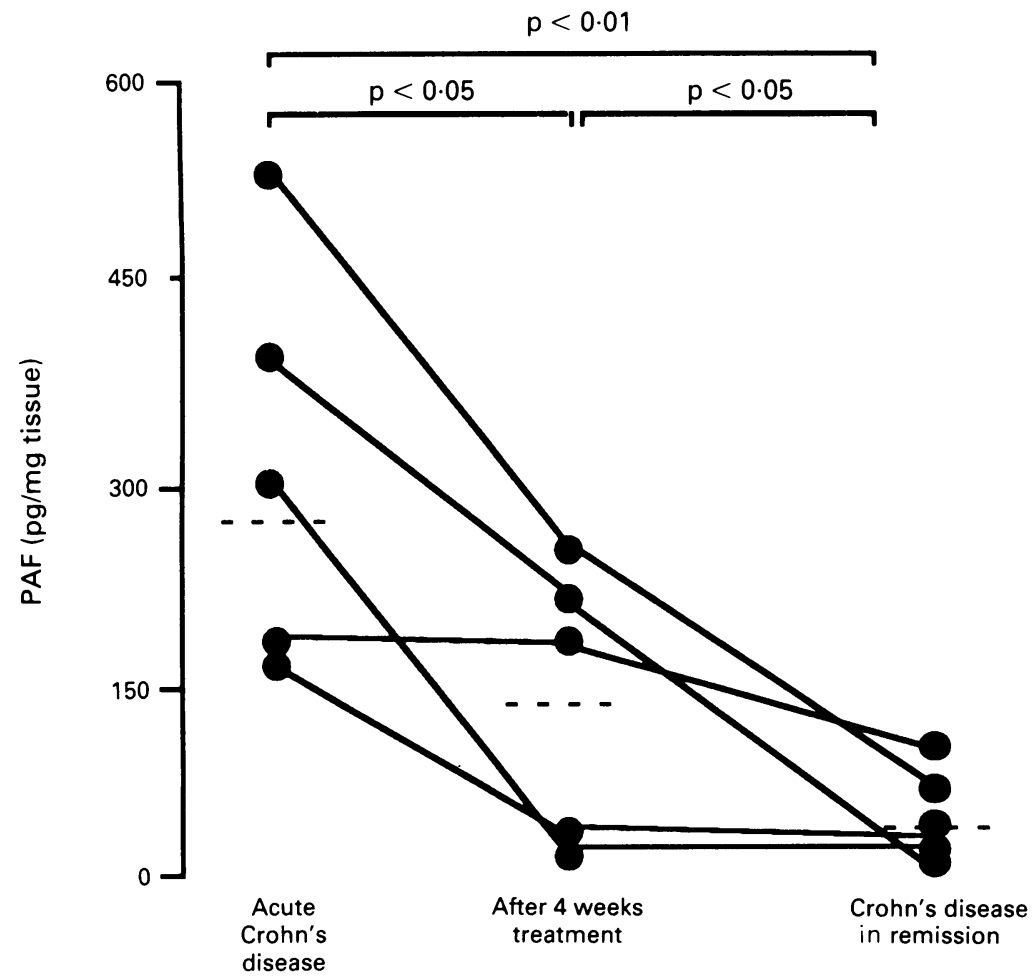

Figure 5: Each point denotes a patient with Crohn's disease with a follow up during prednisolone therapy (four weeks) and in remission (three to five months after prednisolone therapy beginning). (...) denotes the mean value of colonic paf from all five patients.

acetyltransferase to yield a biologically active platelet activating factor molecule. ${ }^{3+}$ Eliakim et $a l^{19}$ have reported that prednisolone and 5aminosalycilate inhibit colonic platelet activating factor synthesis in vitro. The mechanism of this inhibition is poorly understood. As PLA2 has been shown to be increased in Crohn's disease patients, ${ }^{35}{ }^{36}$ it has been postulated that steroids inhibit colonic platelet activating factor synthesis by interfering with $\mathrm{PLA}_{2}$ activity. The fact that lyso platelet activating factor concentrations are not significantly enhanced in acute Crohn's disease mucosa compared with normal mucosa, however, may suggest that raised platelet activating factor levels are related to an increased acetyltransferase rather than to PLA $\mathrm{P}_{2}$ activity. The role of specific acetyltransferase activity in Crohn's disease patients has not been studied so far, and deserves investigation. It is unknown whether high activity of enzymes is related to change involving the inflammatory cells or both intestinal epithelial and inflammatory cells. Therefore we suggest that platelet activating factor should be considered as a global mucosal activity marker.

Because no significant difference was observed between colonic platelet activating factor content from the left or right sides of the colon and was unrelated to the extent of disease, biopsies from sigmoid may reflect the levels of platelet activating factor in the whole intestine.

In conclusion, the colonic platelet activating factor is raised in acute Crohn's disease patients irrespective of the severity or the type of inflammatory cell infiltration. As shown in this study, two biopsies from the left side of the colon are sufficient to assess the mucosal disease activity in Crohn's disease patients whatever the location of the disease. The role of platelet activating factor blocker in the treatment of inflammatory bowel disease deserves investigation.

The authors wish to thank Professor D Jewell and Dr S P L Travis from Gastroenterology Unit of Oxfordshire Health Authority, Oxford, England, for their scientific advices.

1 Donowitz $M$. Arachidonic acid metabolites and their role in inflammatory bowel disease; an update requiring addition of a pathway. Gastroenterology 1985; 88: 580-7.

2 Rask-Madsen J. The role of eicosanoïds in the gastrointestinal tract. Scand f Gastroenterol 1987; 22 (suppl 127): 7-19.

3 Rampton DS, Hawkey CJ. Prostaglandins and ulcerative colitis. Gut 1984; 25: 1399-413.

4 Benveniste J, Hensen OM, Cochrane CG. Leukocytedependent histamine release from rabbit platelets: the role of $\mathrm{IgE}$, basophils and a platelet activating factor. $\mathcal{F} \operatorname{Exp~Med}$ 1972; 136: 1356-77.

5 Pinckard RN, Ludwig JC, McManus LM. Platelet-activating factors. In: Gallin JI, Goldstein IM, Synderman R, eds. Inflammation: basic principles and clinical correlates. New York: Raven Press, 1988: 139-67.

6 Snyder F. Platelet-activating factor and related acetylated lipids as potent biologically active cellular mediators. $A m \mathcal{~}$ Physiol 1990; 259: C697-708.

7 Mencia-Huerta JM, Lewis RA, Razin E, Austen KF. Antigen initiated release of platelet-activating factor (paf-acether) from mouse bone marrow-derived mast cells sensitized with monoclonal IgE. F Immunol 1983; 131: 2958-64

8 Camussi G, Aglietta M, Malavasi F, Tetta C, Piacibello W, Sanavio F, et al. The release of platelet-activating factor from human endothelial cells in culture. F Immunol 1983; 131: $2397-403$.

9 McIntyre TM, Zimmerman GA, Satoh K, Prescott SM Cultured endothelial cells synthesize both platelet-activating factor and prostacyclin in response to histamine, bradykinin factor and prostacyclin in response to histamine, bradykinin

10 Lee TC, Lenihan DJ, Malone B, Roddy LL, Wasserman SI Increased biosynthesis of platelet-activating factor in activated human eosinophils. F Biol Chem 1984; 259: 5526 30

11 Billah MM, Bryant RW, Siegel MI. Lipoxygenase products of arachidonic acid modulate biosynthesis of platelet-activating factor (1-0-alkyl-2-acetyl-sn-glycero-3-phosphocholine) by human neutrophils via phospholipase A2. 7 Biol Chem 1985 ; 260: 6899-906.

12 Sobhani I, Denizot Y, Bourgeois M, Cheret AM, Leroux S Mignon $M$, et al. cAMP-independant paf release by histamine and VIP from the mucosa gastric cell line HGT, mine and VIP from the mucosa

13 Terashita Z, Imura Y, Nishikawa K, Sumida S. Is platelet activating factor a mediator of endotoxin shock? Eur $\mathcal{F}$ Pharmacol 1985; 109: 257-61.

14 Sun XW, Hsueh W. Bowel necrosis induced by tumor necrosi factor in rats is mediated by Platelet-activating factor. $\mathcal{F}$ Clin Invest 1988; 81: 1328-31.

15 Wallace JL, Steel G, Wittle BJR, Lagente V, Vargaftig B. Evidence for platelet-activating factor as a mediator of endotoxin-induced gastrointestinal damage in the rat. Gastroenterology 1987; 93: 765-73.

16 Rosam AC, Wallace JL, Whittle BJR. Potent ulcerogenic actions of platelet-activating factor on the stomach. Nature 1986; 319: 54-6.

17 Konturek SJ, Brozowski T, Drozdowicz D, Garlicki J, Beck $\mathrm{G}$. Role of leukotrienes and platelet-activating factor in acute gastric mucosal lesions in rats. Eur F Pharmacol 1989; 164 285-93.

18 Gonzalez-Crussi F, Hseuh W. Experimental model of ischemic bowel necrosis. The role of platelet-activating factor and endoxin. Am 7 Pathol 1983; 112: 127-35.

19 Eliakim R, Karmeli F, Razin E, Rachmilewitz D. Role of platelet-activating factor in ulcerative colitis. Enhanced production during active disease and inhibition by Sulfasalazroduction during active disease and inhibition by Sulfasala-

20 Kald B, Olaison G, Siödhahl R, Tagesson C. Novel aspect of Crohn's disease: increased content of platelet-activating frohn's disease: increased content of platelet-activating 204.

21 Denizot Y, Chaussade S, Colombel JF, Benveniste J, Couturier D. Presence of paf-acether in stools of patients suffering from inflammatory bowel disease. $C R$ Acad $S c$ 1991; 312: 329-33.

22 Morson BC. Histopathology of Crohn's disease. Proc $R$ So Med 1968; 95: 1167-72.

23 Jouvin-Marche E, Ninio E, Beaurain G, Tencé M, Niaudet P Benveniste J. Biosynthesis of paf-acether (platelet-activating factor). Precursors of paf-acether and acetyl-transferase activity in human leukocytes. F Immunol 1984; 133: 892-8.

24 Denizot Y, Sobhani I, Rambaud JC, Lewin JMJ, Thomas Y, colitis and its inhibition by steroids and sulfasalazine. colitis and its inhibition by steroids and sulfasalazine.
cells. (INT407). Scand $\mathcal{F}$ Gastroenterol 1989; 24: 475-84.

25 Cazenave JP, Benveniste J, Mustard FJ. Aggregation of rabbit platelets by platelet-activating factor is independent of the platelets by platelet-activating factor is independent of the release reaction and the arachidonate pathway and inhibited

26 Nunez D, Chignard M, Lorth R, Le Couedic JP, Norel X, Spinnewyn X, et al. Specific inhibition of paf-acether induced platelet activation by BN 52021 and comparison with the paf-acether inhibitors kadsurenone and CV 3988. Eur F Pharmacol 1986; 123: 197-205.

27 Benveniste J, Le Couedic JP, Polonsky J, Tencé M. Structura analysis of purified platelet-activating factor by lipases. Nature 1977; 269: 170-1. 
28 Tencé M, Polonsky J, Le Couedic JP, Benveniste J. Release, purification and characterization of platelet-activating factor (paf). Biochimie 1980; 62: 251-9.

29 Sharon O, Ligumsky M, Rachmilewitz D, Zor U. Role of prostaglandins in ulcerative colitis. Enhanced production prostaglandins in ulcerative colitis. Enhanced production
during active disease and inhibition by sulfasalazine. Gastroenterology 1978; 75: 638-40.

30 Zifroni A, Teves AJ, Sachar DB, Rachmilewitz D. Prostanoid synthesis by cultured intestinal epithelial and monoculear cells in inflammatory bowel disease. Gut 1983; 24: 659-64.

31 Ligumsky M, Karmel F, Sharon P, Zor U, Cohen F, Rachmilewitz D. Enhanced thromboxane $\mathrm{A}_{2}$ and prostaRachmilewitz $\mathrm{D}$. Enhanced thromboxane $\mathrm{A}_{2}$ and prosta-
cyclin production by cultured rectal mucosa in ulcerative cyclin production by cultured rectal mucosa in ulcerative
colitis and its inhibition by steroids and sulfasalazine Gastroenterology 1981; 81: 444-9.
32 Sharon P, Stenson WF. Enhanced synthesis of leukotriene B4 by colonic mucosa in inflammatory bowel disease. Gastroenterology 1984; 86: 453-60.

33 Gustafson C, Tagesson C. Phospholipase $\mathrm{A}_{2}$ activation and Arachidonic Acid Release in cultured intestinal epithelial cells. (INT 407). Scand f Gastroenterol 1989; 24: 475-84.

34 Ninio E, Mencia-Huerta JM, Heymans F, Benveniste Biosynthesis of platelet-activating factor. I. Evidence for an acetyltransferase activity in murine macrophages. Biochim Biophys Acta 1982; 710: 23-31.

35 Olaison G, Leanderson P, Sjödhal R, Tagesson C. Increased phospholipase A2 activity of colonic mucosa in Crohn's colitis. Digestion 1989; 43: 228-33.

36 Olaison G, Siödhal R, Tagesson C. Increased phospholipase A2 activity of ileal mucosa in Crohn's disease. Digestion $1988 ; 24: 136-41$ 